\title{
SOCIOMORFOLOGÍA EN LA CIUDAD ISLÁMICA TRADICIONAL
}

\author{
Lic. D. ${ }^{a}$ Silvia Rico Botella \\ Universidad Católica de San Antonio. Murcia. España
}

\section{PRESENTACIÓN}

La siguiente ponencia "Sociomorfología de la ciudad islámica clásica" es una aproximación interpretativa de la ciudad musulmana tradicional, en tanto que ésta se construye en relación a una serie de factores socioculturales.

Antes de abordar el grosso de la ponencia voy a tratar algunas cuestiones epistemológicas, atendiendo a un modo de proceder consistente en la explicación de los conceptos a partir de la exploración de otros conceptos, a modo de una especie de deconstructivismo, hasta conseguir desengranar los distintos elementos que van a ir apareciendo a lo largo del contenido de la misma.

De esta manera, en esta reflexión teórica se pueden distinguir tres partes bien diferenciadas: una referida a la significación del concepto sociomorfologia y su objeto de estudio; otra referida a algunas cuestiones generales sobre qué podemos considerar por ciudad, y por último, una interpretación sociomorfológica de la ciudad musulmana clásica.

\section{DEL CONTENIDO SOCIOMORFOLÓGICO}

Teniendo en cuanta que el mundo empírico que nos rodea se expresa a través de múltiples manifestaciones y soportes, cuando se trata de averiguar los entresijos sociales y culturales de una época presente o pasada, la observación de los materiales que dejaron, y en concreto el hecho constructivo, asi como los elementos icónicos que lo envuelven, se revelan fabulosos informantes sociales y culturales.

En esta tarea, la sociologia interpretativa, o sociomorfología, se convierte en un potente instrumento de interpretación de las formas arquitectónicas urbanas. Y digo urbanas, porque en esta disciplina no interesa el elemento aislado, sino su inclusión dentro de un entramado o red más amplia, la ciudad, ya que lo urbano es el espacio donde además de denotar funciones materiales precisas, connotan presupuestos ideológicos de la estructura social conformada por aquellas relaciones'.

1 Diaz Orueta, F. \& Mira, E. "Por un sociologia de las formas arquitectónicas" en Pensar" y vivir lar ciudad, Departamento de Ciencias Sociales, Universidad de Alicante, 1995. 
En las ciudades, la arquitectura es tan expresiva en sus presencias como en sus ausencias, y lo es porque ella misma, así como la forma urbana son receptáculos de la cosmovisión de la sociedad que las produce. $Y$ como sabemos, cualquier sociedad, pudiendo definir la misma, como un grupo de individuos que interactúa, que reconoce una pertenencia en común, y cuya interacción está regulada por unas normas o pautas de comportamiento, es inseparable del componente cultural que la envuelve. Así, la cultura, y tal y como la definiera Tylor en 1871, en tanto que "cultura o civilización es ese todo complejo que incluye conocimientos, creencias, artes, morales, leyes, costumbres, y cualquier otra capacidad o hábito adquirido por el hombre en tanto que miembro de una sociedad determinada" se convierte en una especie de cajón desastre que dota de sentido a lo social. Pero no se trata de una relación unívoca, ya que a su vez, lo social aporta significación a lo cultural, y aquí no vamos a entrar en intrincados debates sobre la preeminencia de lo social sobre lo cultural o viceversa, sino que precisamente ambos dos ( cultura y sociedad) son componentes que se entrelazan para justificar la diversidad humana.

De esta manera, la sociomorfología, y sin pretensiones de reclamar exclusividad, es capaz de descifrar las distintas facetas de la arquitectura más allá de su hecho funcional, más allá de los presupuestos teóricos benthamianos que tan bien supieron adoptar los arquitectos funcionalistas como Le Corbussier. Y lo es -me refiero a la pluralidad de facetas de la arquitectura-, porque los individuos además de necesitar la construcción de un lugar para guarecerse de las inclemencias climáticas, respondiendo a una de las necesidades primarias de la humanidad, es un ser simbólico que transforma la simpleza de cualquier material constructivo en simbiosis creativa y relacional con el entorno que le rodea, entendiendo por entorno tanto el medio natural como el sociocultural.

Si anteriormente hemos afirmado que el ser humano se revela como un ser simbólico, no es extraño que afirmemos que la arquitectura, y por ende la ciudad, es susceptible de ser analizada desde un punto de vista semiótico. Pero, qué entendemos por semiótica. Ésta ha de entenderse como la ciencia que estudia los fenómenos socioculturales como si fueran sistemas de signos, en definitiva, que producen comunicación.

Así, el examen fenomenológico de la arquitectura, como los de diseño y proyección urbanística, se convierte en una especie de juego intelectivo, en la que in crecendo vamos obteniendo claves explicativas de los fenómenos socioculturales que retroalimentan dicha creación. Es decir, y sin intención de que pudiera parecer un galimatías, el análisis semiótico podrá denotar y connotar las funciones en su aspecto comunicativo, y definirlas mejor en cuanto que funciones, descubriendo nuevos tipos de funcionalidad, más allá de la mera consideración funcional.

Por ello, el hecho arquitectónico se revela como un lenguaje compuesto por un sistema de signos, que es capaz, tal y como afirma Koening, de promover comportamientos. Esta capacidad de promover comportamientos no debe entenderse en un sentido unidireccional, ya que como sabemos, y tal y como fundamentan los representantes del interaccionismo simbólico desde la Escuela de Chicago, y en particular Max Weber desde su teoría de la acción social, el ser humano interactúa y se relaciona con otros individuos y objetos. 
Además, esta acción, y no es gratuito el adjetivo social, representa el salto de lo individual a lo social, de lo subjetivo a lo intersubjetivo, y entre sus características es destacable la de su carácter simbólico. El carácter simbólico de la acción social hace referencia a la existencia de un mecanismo de interpretación simbólica de la acción de los otros, y un proceso de elaboración de una respuesta efectiva, en tanto que el individuo es portador de cultura.

Un factor que no ha de olvidarse a la hora de analizar cualquier componente sociocultural son los procesos de cambio. El cambio es un hecho brutal, es condición de vida, es algo cuya existencia no puede ser negada, y en el curso de la Historia hay procesos de cambio en las que las distintas funciones, connotadas y denotadas, están sujetas a pérdidas, recuperaciones y sustituciones de toda clase. Pérdidas, recuperaciones y sustituciones impresas por el devenir existencial, y que constituyen el soporte gráfico del lector que intenta descifrar los sentidos que aquéllos dotaron.

\section{DE LA CIUDAD}

Hecha esta introducción sobre qué entendemos por sociomorfologia, y habiendo justificado la necesidad de un análisis interpretativo del espacio desde la perspectiva de la ciudad, cabe tener en cuenta algunas consideraciones especiales sobre esta última. Es decir, si anteriormente hemos desmenuzado la significación y objeto de estudio de lo sociomorfológico, voy a proceder de la misma manera sobre el concepto de ciudad, para asi poder descubrir algunos elementos que posteriormente resultarán útiles para especificar algunas rasgos generales sobre la ciudad musulmana.

Toda ciudad constituye una categoría de naturaleza compleja ya que está definida por una serie de elementos constitutivos que remiten a la interacción social, y por lo tanto a la confluencia de una serie de factores socioculturales, económicos y políticos. Es precisamente a través de esa continua interacción cuando se generan una serie de elementos, que permiten afirmar que efectivamente estamos en presencia de un espacio urbano, entre otras: asentamientos no dispersos, mercado, comunidad vecinal, lugares de culto...

Brevemente diremos que el surgimiento de las ciudades se remonta al año 3.500 a.C., en los valles fluviales del Nilo en Egipto, del Tigris - Eufrates, y del Indo. A pesar de la variedad de las civilizaciones, algunas características generales de la mayoría de las ciudades del mundo antiguo nos permiten definir una serie de rasgos comunes entre otras: suelen estar fortificadas; existe un área central ocupada a menudo por un gran espacio público, que en ocasiones puede estar amurallado; existencia de un mercado y de edificios principales que son casi siempre de carácter político y/o religioso; las viviendas de la clase dirigente o élite suelen concentrarse en el centro o cerca de él, mientras que los menos privilegiados suelen situarse en los límites de la ciudad.

Con el paso del tiempo, la morfología de las ciudades indiscutiblemente ha ido variando. Podemos establecer una tipología sociohistórica de las mismas, de entre las cuales es destacable la elaborada por Henri Lefebvre. El concepto central en la obra de este autor en 
su análisis socioespacial es el de producción del espacio ${ }^{2}$. Este concepto remite a la noción de universal concreto de Hegel, es decir, que aún teniendo las características de lo universal, esta universalidad está sujeta a la historia y a un momento concreto. El universal concreto existe en y a través de los particulares que son distintos y él mismo a la vez.

Según Lefebvre cada sociedad, con su distinto modo de producción, proyecta su espacio. Este espacio, que es un espacio social, incluye las relaciones sociales de producción y las relaciones de producción. Como marxista, Lefebvre considera que existe historia cuando existe producción y proceso productivo. Por ello es necesario determinar la función que desarrollan las fuerzas productivas y las relaciones de producción en la configuración del espacio. Las contradicciones que surgen en las relaciones sociales de producción generan la transición de un modo de producción a otro, y esta transformación se traduce en la disolución contemporánea del espacio así como se definía en el modo de producción precedente.

Lefebvre señala las fases de una historia del espacio, señalando la periodización relativa de los distintos modos de producción. La secuencia establecida incluye los siguientes tipos de espacio: absoluto, histórico, abstracto, contradictorio y diferencial. El espacio absoluto es un lugar natural preseleccionado que transforma en símbolo el elemento naturaleza. De este espacio se pasa al espacio histórico, que es un espacio relativizado y animado por un sujeto colectivo; este espacio se corresponde con el espacio de la ciudad histórica occidental. El espacio abstracto, en cuanto que producido por el Capitalismo, es un espacio paradójico porque constituye simultáneamente el conjunto de los lugares que desencadenan las contradicciones. Asi pues, se concreta sobre el suelo ese proyecto de división social y técnica del trabajo. Posteriormente, el espacio de contradicción prepara el espacio diferencial que se realizará como antítesis del espacio abstracto.

Como vemos, el esquema sintético de la historia social del espacio urbano según Lefebvre hace que los tipos fundamentales del espacio se correspondan con los distintos modos de producción ya introducidos por Marx, y que se corresponden con una secuencia de la evolución histórica, tal que: asiática, clásica, feudal, burguesa, y, capitalista.

Otro de los autores que establece un análisis sociohistórico y evolutivo de la tipología de asentamientos urbanos es Max Weber. Según este autor, existen una serie de características que nos permiten catalogar las ciudades, entre otras, la función económica y la función político-administrativa. Contemplada desde una perspectiva económica, la ciudad es un asentamiento con una fuerza económica autónoma que influye sobre el resto del territorio. Hablaremos, por tanto, de ciudad cuando podamos definirla en términos de localidad de mercado, es decir, con un mercado local que permite una especialización de la producción económica. En este punto es destacable no confundir dicha función económica con el oikos, que se corresponde con una ciudad-principado, en la que el sujeto no es un verdadero sujeto económico porque está condicionado por la capacidad de adquisición de la administración del príncipe.

2 Bettin, G. Las sociólogos de la ciudad. Ediciones GG, Barcelona 1982. 
Siendo consciente Weber que la definición económica resulta poco extensiva para la caracterización de los fenómenos sociales, y en concreto, para la definición de la ciudad, va a utilizar una confrontación de fenómenos económicos, sociales y políticos para abordar la investigación histórica de aquellos factores capaces de explicar el desigual desarrollo de las formas urbanas.

El problema de las relaciones entre la esfera politica y la esfera económica reviste particular importancia en esta meta. La relación existente entre estas esferas es la siguiente: los grupos son el sostén de las actividades, de los intereses y de los sistemas económicos; el desarrollo de la actividad económica depende de la lucha política entre estos grupos. La realización del mercado depende, entonces, del conjunto de leyes que recurren a los elementos constitutivos de las instituciones políticas. Una característica importante del concepto politico de ciudad será la de existencia de una sede de fortaleza y de una guarnición.

Como los dos autores anteriormente tratados dan preeminencia a una perspectiva economicista para establecer una tipologia de ciudades, y siendo consciente de que obvian otras variables igualmente importantes como las culturales, finalmente mostraré el análisis de Horacio Capel sobre el espacio urbano.

Según este autor la conformación histórica ${ }^{3}$ de las ciudades se ha definido en función de una serie de variables actitudinales, comportamentales y morales. Capel elabora una síntesis diacrónica de las ciudades en las que ha sido determinante el papel atribuido a la esfera de los valores. Siguiendo este análisis, podríamos decir, por ejemplo, que Jerusalén, ciudad santa, elegida por Dios como centro de la religión mosaica y cabeza del reino mesiánicao, aparece como lugar de salvación. Pero también, más frecuentemente, la ciudad es el lugar de vicio y de corrupción, como por ejemplo, Babilonia, Sodoma y Gomorra.

También en la época romana imperial, la ciudad es vista como fuente de corrupción. Escritores como Virgilio y Horacio muestran en sus escritos el horror a la vida de la gran metrópolis y ensalzan el retiro al campo como lugar bucólico.

Durante el Renacimiento la concepción de la ciudad corre la misma suerte. Tres son las fuentes durante esta época que posibilitan el sentimiento antiurbano: la valoración bucólica de la Arcadia ideal, y la vuelta a la naturaleza; el menosprecio de la Corte y la alabanza de la aldea; y el mito del buen salvaje.

En la Ilustración existe una actitud ambigua de la ciudad. En general existe un sentimiento de valoración positiva de lo urbano, ya que para muchos sólo es posible la vida es este medio. Así, en Francia, Voltaire elogia Paris, mientras que los fisiócratas, muestran un despego e incluso hostilidad hacia la ciudad, repitiéndose a valoración del campo y la agricultura. En el siglo XIX, Engels hace lo propio con la descripción de las ciudades inglesas tras la Revolución Industrial, o como también lo hace el escritor R. Dahl en su obra Charlie y la fábrica de chocolate.

3 Capel, H. "Gritos amargos sobre la ciudad", en VV.AA. Desde la ciudad (Actas de Arte y Naturaleza), Huesca, 1998. 
En EE.UU durante el Romanticismo, se reelabora y refuerza el sentir antiurbano, que coexiste con un sentimiento de admiración y atracción hacia la ciudad, y hacia lo que ésta representa de cultura, democracia y progreso.

Ya en el siglo XX, algunos pensadores como los sociólogos de la Escuela de Chicago, denunciarían la falta de sociabilidad, carencia de higiene, vicios, delitos, provocados por la ciudad en un intento de mostrar la relación entre los diferentes rasgos de la situación en las ciudades y de la "cultura urbana" con las condiciones ecológicas propias de la ciudad: dimensión, densidad y heterogeneidad social. O como haría Georg Simmel en su obra "Las grandes ciudades y la vida del espiritu", quien vio en el crecimiento de las ciudades un peligro de descomposición social y pérdida de valores.

Estas concepciones críticas de la ciudad propias del pensamiento antiurbano y defendidas por escritores, románticos, reformadores sociales, médicos nos dan una visión sesgada de la misma. Porque aunque no se pueden negar los graves problemas que se originan en las ciudades, estos no son ocasionados directamente por la urbs sino por la sociedad.

Pero las ciudades no sólo generan males, ya que éstas también han de ser consideradas como lugar de progreso, de creatividad y de innovación, de vida intelectual intensa, de la ciencia y de la cultura, de la libertad, de la educación, de la mayor capacidad de interacción, de la movilidad social...

\section{DE LA CIUDAD ISLÁMICA}

Tras esta breve y comprimida aproximación sobre la sociomorfologia y la ciudad, nos resta analizar la ciudad islámica tradicional. Como puede parecer una pretensión harto presuntuosa, tres van a ser los elementos a partir de los cuales articular dicha interpretación, a saber: la vivienda, el mercado (zoco) y la mezquita. Siendo consciente del amplio espectro geográfico que abarca dicho cultura, voy a limitar el análisis temporal de la ciudad islámica a sus orígenes, estableciendo un tipo ideal. Aquí por tipo ideal habremos de entenderlo tal y como lo define Max Weber, a saber: una descripción abstracta, construida mediante la acentuación de ciertas características de los casos reales con el fin de destacar con precisión sus peculiaridades más esenciales. ${ }^{4}$

La elección de estos tres elementos lejos de ser arbitraria, servirá de eje argumental para articular el discurso, ya que sería estéril hablar de la existencia de tales elementos sin establecer relaciones. Es decir, así como no hay sistemas sin entorno, o entornos sin sistemas, asi tampoco hay elementos sin una vinculación relacional, o relaciones sin elementos. Los elementos pueden numerarse y, de acuerdo con su cantidad, se puede calcular matemáticamente el número de relaciones posibles. Sin embargo, ello reduce las relaciones entre los elementos a una expresión cuantitativa. Los elementos adquieren cualidad sólo al considerárseles relacionalmente, es decir, si se relacionan unos con otros. 


\subsection{Sobre los orígenes del Islam y su cultura}

Por lo que hace al surgimiento de la ciudad musulmana, y por lo tanto a los origenes de la civilización islámica, huelga decir que ésta no surge como caída del cielo. Tras la vorágine y azarosa época del Imperio Romano y el triunfo de la Cristiandad, más lejos, en Asia Menor, en la Península Arábiga, surge un movimiento religioso, cultural y político, cimentado sobre las bases establecidas en el Corán y reveladas al profeta Muhammad Mahoma. Este movimiento religioso y cultural se expande desde sus inicios, siglo VII, a través de un viaje de conquistas, en las que sucumben Oriente Medio, la India y el norte de África, parte de Bizancio, y la parte sur del Norte del Mediterráneos. De la rapidez en la expansión del Islam, es buena prueba el hecho de que en menos de cien años, los musulmanes alcanzaran la costa atlántica de África.

Como consecuencia de la rápida expansión geográfica del Islam, son varios los préstamos exteriores asimilados por esta cultura que han concurrido a forjar una civilización que ha logrado conservar unos valores y un estilo peculiares. La civilización islámica realiza fenómenos de sincretismo en todos aquellos lugares en los que se asienta, convirtiéndose en una cultura dominante. $Y$ ello, porque asume la continuidad de las tradiciones y valores de los lugares conquistados, siempre y cuando no entren en contradicción con el Islam, pero introduciendo también una serie de fuertes cambios en algunos aspectos de cada cultura.

Un punto a tener en cuenta, es la distinción entre la cultura árabe y la cultura islámica ${ }^{6}$. Algunos consideran que la cultura islámica constituye una prolongación de la cultura árabe preislámica y una exaltación de los valores culturales originales. Pero esta concepción es una verdad a medias, ya que si el Islam se apropia de ciertos valores culturales árabes anteriores a su advenimiento, los articula en forma diferente y les otorga una nueva función que produce una cultura propia.

Así, uno de los elementos de identidad de la cultura islámica es el sentimiento de pertenecer, antes que nada, a la comunidad de creyentes': mientras que la comunidad de creyentes o la umma sea experimentada como una realidad, la cultura que constituye su expresión será la islámica. Otro elemento de identidad islámica es el apego a la lengua y escritura árabe, que para todo musulmán constituye un medio de profundizar en la fe y de insertarse mejor en la cultura islámica. Pero no hay que entender la cultura islámica como una cultura cerrada, más bien al contrario es una civilización abierta hacia el interior y abierta hacia el exterior, ya que la apertura constituye uno de los elementos de su identidad.

5 Risebero, B. Historia dibujada de la arquitectura. Celeste ediciones, Madrid, 1991.

6 Guiga, T. "Aspectos de la cultura islámica”, en CuIturas, volumen VII, n” 4, UNESCO.

7 La umma: esta comunidad de creyentes no está identificada con un espacio geográfico concreto, sino al individuo, a la comunidad. Es una realidad espacial y temporal, que vincula a los individuos por encima del espacio geográfico y de la nacionalidad. El Islam no es sólo una religión, es sobre todo, una forma de vida singular y característica, una cultura que identifica a los musulmanes, a la Umma, más allá de las diferencias nacionales. 
En esta elaboración identitaria de la civilización islámica, son fundamentales el reconocimiento de tres fuentes a partir de las cuales dicha cultura se configura como unidad: el Corán, la Tradición del Profeta (sunna) y las enseñanzas orales y escritas de los juristas ${ }^{8}$.

\section{- El Corán}

Éste contiene todos los elementos esenciales del "dogma" islámico y su ley. Su mensaje principal es la proclamación de la Unidad Divina, la absoluta Trascendencia del Principio respecto de todas las manifestaciones, y la situación de total dependencia de la criatura respecto a Dios (Allah). Este mensaje se condensa en las dos fórmulas del "testimonio de la fe", cuya declaración confiere a todo hombre de buena voluntad la condición de musulmán. Esta primera fórmula declara que "No hay más Dios que el Uno y único" (Allah); y la segunda afirma que "Mahoma es el mensajero de Dios".

\section{- La tradición del profeta}

Ella se refiere a que Mahoma ha de ser considerado como el Corán puesto en obra. Mahoma es al mismo tiempo el portador de la ley islámica y la manifestación de la Verdad Universal. La Sunna recoge los actos y dichos (hadith) del Profeta a lo largo de su vida. Por medio de la Sunna el musulmán tiene una guía de comportamiento práctico cotidiano que debe seguir en todos los momentos de su vida.

\section{- La jurisprudencia}

Por lo que hace a la jurisprudencia, ni el Corán ni la Sunna se presentan como colecciones de leyes religiosas coherentes y organizadas. Durante la implantación de la dinastía omeya, se crean una serie de compendios de doctrina coherentes, asi como todas las prescripciones necesarias para la buena conducción de la Comunidad Islámica. Este empeño por codificar la jurisprudencia origina la aparición de los cuatro "métodos" o escuelas del Islam sunní. En todos los casos se trata del cuerpo entero de prescripciones que gobiernan los actos de los creyentes en sus más mínimos detalles.

Además de las tres fuentes principales citadas anteriormente, existen cuatro instituciones comunes a todos los musulmanes: la oración, el ayuno, la limosna y la peregrinación. La oración es la clave del Islam, celebrada cinco veces al día, puntúa con su ritmo la vida del individuo. La oración como el ayuno es obligatoria para todo musulmán "responsable", es decir, para todo adulto de mente sana. Además, determinadas condiciones que preceden o acompañan al cumplimiento de la oración influyen considerablemente sobre el diseño y funcionamiento de las ciudades del Islam. Así, por ejemplo: a) el estado de pureza ritual, logrado por medio de las abluciones; b) el respecto al momento específico de la oración; c) la orientación hacia La Meca ; d) la existencia de un lugar lo bastante amplio como para poder acomodar a todos los fieles en la oración comunitaria del viernes a mediodía, que es obligatoria en todos los núcleos de población de cierta importancia.

La primera exigencia obliga a la dotación de aseos, albercas, fuentes y baños públicos, cuyas cúpulas bastan para denotar la existencia de una ciudad islámica. La segunda da lugar 
a la creación de las funciones del muwaqqit, funcionario que elabora los horarios, y del muecín, que convoca a la oración. Oración que será dirigida por el iman desde un punto determinado de la mezquita, orientado hacia La Meca (al-quibla). Esto, a su vez, lleva a la construcción de alminares y, en determinadas capitales, de observatorios astronómicos. Las dos últimas exigencias determinan cómo deben ser edificadas las mezquitas y cumplidas sus exigencias litúrgicas.

\subsection{El espacio urbano musulmán tradicional}

Por lo que hace a la forma del plano, la cultura islámica configura el espacio urbano según el tipo de ciudades geomórficas u orgánicas, en contraposición a las plantas reticulares (también llamadas en cuadrícula) y a su vertiente grande manière, que busca grandes perspectivas y escenografias. Esta unidad orgánica configura un tejido urbano denso, y altamente compacto, en la que raras veces se aprecian fisuras.

En las ciudades musulmanas, grosso modo, se pueden distinguir tres espacios concéntricos intramuros: el alcázar, la alcazaba y la medina. Los delegados del poder residen en el alcázar, mientras que la alcazaba se constituye como una ciudad administrativa. Por su parte la medina musulmana, está vertebrada por la mezquita mayor.

La ciudad musulmana clásica se puede definir como una serie de tensiones entre polos contradictorios sujetos a las variantes del tiempo y el espacio. La ciudad es comercial y artesanal, pero buena parte de su riqueza se deriva de la agricultura, y la separación fisica entre la ciudad urbana y el cultivo de la tierra no queda demasiado clara. La ciudad queda definida por una sola mezquita congregacional, pero también es cierto que contiene cientos de santuarios y lugares de rezo privados. Además de una burguesía local existe una aristocracia militar de gobernadores que ostenta casi todo el poder.

Los barrios están divididos por agrupaciones tribales, religiosas o étnicas, pero el núcleo de la ciudad es su centro comercial, en el que coexisten las tendencias religiosas. Las murallas tienen la misión de protegerla, y los arrabales crecen en torno a ellas. Los objetos y funciones de la ciudad se derivan de las necesidades de la ciudad?.

\section{- Casa musulmana tradicional}

Ésta retoma de la vivienda romana, tanto de la domus como de la villae, organizadas en torno a dos espacios -el impluviuum y el persitiluum - el sentido de privacidad. Pero esto exclusivamente, ya que si bien el Imperio Romano hizo gala durante siglos de su fastuosidad y poderío reflejándolo en la arquitectura de manera ostentosa, por su parte, la arquitectura musulmana caracterizada por la exactitud y habilidad geométrica desarrolla sobremanera las artes abstractas aplicadas, con formas naturales y evolucionadas de la caligrafia árabe.

La casa musulmana llamada a servir de modelo tanto a la vivienda privada como a la mezquita, es la casa donde el profeta vivía en Medina ${ }^{10}$. La vivienda privada se cierra a un

9 Lewis, B. El mundo del Islam, gente, cultura, fe. Ediciones destino, Barcelona, 1995.

10 Bammate, Nadjn oud- Dine."El espacio del Islam" en Culluras volumen V, $n^{\circ} 4$. UNESCO, 1978 
espacio interno que es el de la intimidad. Los lados se reservan a la vida cotidiana, mientras que en los planos más clásicos el centro suele estar ocupado por un patio interior, un jardincillo, a ser posible refrescado por un surtidor. Además, no hay nada más extraño a la cultura islámica que la noción de fachada, que es sustituida en el mundo musulmán por un muro alargado y continuo. Así, la casa, vista desde el exterior, se aprecia como si fuera ciega, ya que incluso se enrejará la ventana, que permite ver sin ser visto.

Si la calle occidental se muestra animada por el ir y venir de los transehuntes, en la cultura islámica, ésta se configura como una especie de prolongación de la vivienda. El sentido de opulencia en la ciudad musulmana clásica no se denota, ya que la totalidad del espacio urbano está conformado por la continuidad, la uniformidad y la impersonalidad del conjunto. Las viviendas de los ricos y de los pobres están mezcladas en sus calles, y es hasta que no se penetra en la casa cuando se puede apreciar la fastuosidad de la misma.

\section{- Mezquita}

La mezquita es el lugar de oración, pero no sólo esto ya que sirve para congregar y albergar la comunidad, propiciando los encuentros humanos y la comunicación. La mezquita, al igual que las viviendas, también tiene un espacio interior, que en ocasiones se constituyen como la superficie más vasta en extensión no edificada. Con el paso del tiempo, la mezquita también se constituirá como representación del poder, como aula de enseñanza, como hospital $o$ asilo. Es este espacio no sólo un lugar sagrado sino también un espacio político y social, ya que el patio central de la mezquita sirve de lugar de intercambio de ideas, así como de cohesión de la comunidad.

La mezquita comprende tres elementos permanentes" ${ }^{\prime \prime}$ el mihrab, hueco practicado en uno de sus muros, absidiola que indica la dirección a la Meca; el mimbar, púlpito o cátedra del predicador; y el minarete, torre desde lo alto de la cual se llama a ala oración. Puede verse en estos tres espacios de la mezquita otras tantas expresiones de la palabra: la que reza, la que predica y alecciona, y la que convoca a la comunidad. Aparte de estos tres elementos mencionados, no hay más en la mezquita que el vacío del espacio punteado por los ritmos de la caligrafia y del arabesco. Más tarde, se podrá cubrir en todo o en parte el patio interior, rematarlo con cúpulas, dado el carácter universal e inmediato del simbolismo de la cúpula en cuanto que representación de la bóveda celeste.

Habiendo afirmado que la mezquita no es sólo el lugar de culto, analizaremos la misma como institución de enseñanza. La mezquita es una institución de enseñanza, entendiendo por enseñanza la actividad sistemática destinada a adquirir y transmitir el saber en instituciones creadas, parcial o básicamente, para dicha finalidad ${ }^{12}$. Pero también ha de entenderse por enseñanza las influencias sociales y personales que conforman la cultura y la conducta de los grupos y de los individuos.

11 Ibidem

12 Nashabi, H. "Instituciones de enseñanza", en R.B. Sejeant, La ciudad islámica, Serbal/UNESCO, 1982 
Los inicios más tempranos de la enseñanza musulmana pueden retrotaerse a La Meca, en tiempos del profeta Mahoma. Históricamente, la primera y probablemente la más importante, de estas instituciones es la mezquita. Constituye un hecho notable que la mezquita, en su calidad de institución de enseñanza, sea el primer instrumento, y el más eficaz, ya que contribuyó a la transición de la sociedad árabe desde un estadio primitivo, a un estadio más desarrollado, basado en la tradición escrita. De esta manera, el estudio del Corán se convierte en el núcleo central de la actividad educativa sistemática. Tanto es así, que la lectura, la escritura y la aritmética están destinadas primordialmente a la mejor comprensión y valoración del texto coránico, y a la aplicación de lo que éste enseña.

\section{- Zoco}

Éste suele extenderse a partir de las puertas de la mezquita, a la que se ciñe, provocando así la no ruptura del espacio sino la reciprocidad entre el ámbito religioso y el lugar profano. Este vínculo entre la mezquita y el mercado responde a una antigua tradición arábigoislámica, ya que la Meca era, simultáneamente lugar de peregrinación y centro comercial. Vemos así como han perdurado una serie de instituciones que son reacias al cambio, ya que como afirma William Oghburn hay que entender la naturaleza de la persistencia o resistencia de la cultura al cambio, la cual podria ser explicada por el poder de conservadurismo en la vida social, el poder de la costumbre, de la tradición, del hábito, así como por la simple inercia. Según este autor, podemos decir que es la utilidad o funcionalidad de un elemento dado de la cultura lo que contribuye en mucho a explicar hasta qué punto ese elemento persiste, generación tras generación, y muchas veces, siglo tras siglo. ${ }^{13}$

Los distintos sectores del zoco se escalonan a partir de la mezquita, a la salida de la cual encontramos en primer término los libreros y los perfumistas, y a continuación los vendedores de tejidos. Seguidamente oficios muy diversos, los curtidores y zurradores. Agrupados de esta manera, los puestos de artesanos y comerciantes proporcionan ocasión para los encuentros humanos así como para las operaciones comerciales ${ }^{14}$.

\section{CONCLUSIONES}

Como hemos visto, la arquitectura y el urbanismo son más que meros instrumentos de protección, resguardo y defensa, ya que poseen la cualidad de instaurarse como códigos simbólicos perennes. En las ciudades, el entorno edificado representa mucho más que el hecho constructivo aislado, ya que se constituyen como el espejo y reflejo de la humanidad. La ciudad es el lugar donde se relacionan formas espaciales y procesos sociales, constituyéndose, así, un espacio social, un espacio relacional. Este espacio relacional no es isomórfico con respecto al espacio fisico, el espacio absoluto. $Y$ no lo es porque hay que hablar de una continua interacción entre espacio fisico y procesos sociales, entendiendo por procesos sociales aquéllos que configuran en espacio social que está compuesto por un conjunto de

13 Nisbett, R. et alter. Cambio social. Alianza Universidad, Madrid, 1993.

14 Op. cit 7. 
sentimientos, imágenes y reacciones con respecto al simbolismo espacial que rodea al individuo.

El estudio morfológico de la dinámica social nos permite descubrir ciertas relaciones existentes entre el entorno construido y la cultura. Ya que la cultura, no es una entidad superorgánica considerada como una abstracción en el cual el papel de los individuos está minimizado. La cultura ha de considerarse como una realidad que no puede ser considerada independientemente de sus portadores humanos. Son ellos quienes permiten el tránsito continuado de generación en generación, quienes reciben, modifican y entregan a las siguientes generaciones todo el bagage de modelos o pautas que denominamos cultura.

\section{BIBLIOGRAFÍA}

BAMMATE, Nadj oud-Dine. "El espacio del Islam", en Culturas, Volumen V, $\mathrm{n}^{\circ} 4$, UNESCO, 1978.

BETTIN, G., Los sociólogos de la ciudad, Ediciones GG, Barcelona, 1982.

CAPEL, H., "Gritos amargos sobre la ciudad", en VV.AA, Desde la ciudad (Actas de Arte y Naturaleza), Huesca,1998.

DÍAZ ORUETA, F. \& MIRA, E., "Por una sociología de las formas arquitectónicas", en Pensar y vivir la ciudad, Departamento de Ciencias Sociales, Universidad de Alicante, 1995.

GIDDENS, A., Sociologia, Alianza Editorial, Madrid, 1998.

GUIGA, T., "Aspectos de la cultura islámica", en Culturas, volumen VII, $n^{\circ} 4$, UNESCO.

LEWIS, B., El mundo del Islam, gente, cullura, fe, ediciones Destino, Barcelona, 1995.

NASHABI, H., "Instituciones de enseñanza", en SERJEANT, R. B., La ciudad islámica, Serbal/UNESCO, 1982.

NISBETT, R. et alter, Cambio Social, Alianza Universidad, Madrid, 1993.

RISEBERO, B., Historia dibujada de la arquitectura, Celeste ediciones, Madrid,1991.

SERJEANT, R. B., La ciudad islámica, Serbal/UNESCO, 1982. 